\title{
As concepções de gênero - ser mulher - de adolescentes do Bairro do Sumaré - Sobral - CE
}

\author{
Maria Inês Sousa, Andrea Astigarraga \\ Universidade Estadual Vale do Acaraú - UVA
}

\begin{abstract}
Resumo
De que maneira as adolescentes entre 15 e 18 anos do bairro Sumaré concebem o que é ser mulher? Pesquisa de abordagem qualitativa, através de oficina pedagógica. $\mathrm{Na}$ relação intercultural, na troca de saberes entre a pesquisadora e as pesquisadas obtivemos vários resultados. O principal foi uma adolescente que transmitiu os conhecimentos adquiridos na oficina para a sua mãe, e esta, que sofria agressões físicas do marido refletiu sobre a sua condição de ser mulher e decidiu mudar de vida, se separou, mudou de casa e adquiriu sua independência pessoal e financeira.
\end{abstract}

Palavras-chave: gênero, interculturalidade, inclusão social, educação

\section{Introdução}

A história da humanidade, pelo menos desde o momento em que surgiu a divisão em classes sociais, é a própria história da segregação e estratificação dos diferentes setores sociais. Os preconceitos de classe, raça, orientação sexual, religião, entre outros são funcionais em menor ou maior grau para a manutenção do status quo. A opressão de gênero não é diferente. A maneira como as mulheres foram marginalizadas ao longo dos séculos impressiona. Utilizou-se de todo tipo de argumento espúrio para mantê-las afastadas da vida pública e submissas ao homem na vida privada. Desde a argumentação religiosa até a argumentação biológica, muitos filósofos, pensadores, juristas, entre outros se esforçaram para manter as mulheres a largo de uma vida digna, autônoma e emancipada.

Nosso trabalho foi desenvolvido com adolescentes entre 15 e 18 anos de idade, que estudam na Escola de Ensino Fundamental e Médio Professora Carmosina Ferreira Gomes, no Bairro do Sumaré, na periferia da cidade de Sobral/CE, neste trabalho buscamos compreender de que maneira elas concebem o que é ser mulher, a situação de opressão e exclusão social, assim como as interfaces da relação intercultural entre as adolescentes pesquisadas e a jovem universitária pesquisadora. As pessoas que habitam nesta comunidade geralmente são indivíduos de baixa renda e escolarização, adictos de drogas, e com características fortemente machistas, ou seja, com predominância de preconceito e desigualdades entre homens e mulheres. O bairro é considerado uma parte da periferia estigmatizada pelo contexto sócioeconômico e cultural da cidade.

Acreditamos que este trabalho seja de extrema importância, principalmente devido os elevados índices de violência contra a mulher, com destaque para aqueles que ocorrem nos setores mais empobrecidos da população. Sabemos também que a própria causa da violência contra a mulher é ainda arraigada a ideia de que as mulheres ainda são propriedades, de alguma maneira, dos homens.

\section{Gênero e adolescência}

Observa-se que esta é uma fase de mudança onde não se é mais criança, mas também não se é adulto é o que Erikson (1968) denomina de moratória social, que é um tempo que a sociedade oferece para seus membros desta faixa etária se desenvolver para exercerem o papel de adulto. Como relacionar o estudo com adolescentes ao conceito de gênero? Como destacar nesta relação a questão de gênero entre adolescentes da periferia?

O conceito de gênero se disseminou a partir da década de 1970. Parte significativa deste termo esta relacionada a um novo olhar sobre a realidade, e distinções entre características femininas e masculinas no que concerne à hierarquia social. Porém, mesmo que os adolescentes tenham a compreensão intuitiva, senso comum, do que é ser homem e mulher eles não conseguem fazer a ligação com o conceito de gênero. O uso de gênero é como "uma maneira de se referir as origens exclusivamente sociais das identidades subjetivas dos homens e das mulheres" (SCOTT, 1990) que surge em meio aos movimentos feministas que lutavam por seus direitos e não se conformavam com as várias formas de discriminação contra as mulheres.

No que concerne a abordagem sobre gênero com adolescentes é perceptível que suas relações entre o meio interno e externo, sua cultura, hábitos, estilo de vida e seus próprios valores estão interligadas as relaçoes de gêneros existente na sociedade, pois:

[...] a produção de indivíduos masculinos e femininos esta intimamente relacionada à identificação de homens e mulheres com o conjunto de normas, valores, funções sociais estabelecidas historicamente para o seu gênero, indissociáveis das expectativas em relação ao outro gênero. (DELGADO 1998, p.16) 
A construção da identidade de um indivíduo se dá no contexto histórico, social e geográfico no qual ele se encontra e com o qual ele interage. Porém, a sua construção é dialética no sentido que o indivíduo ao mesmo tempo em que se forma a partir das experiências concretas de sua realidade, também é protagonista na construção do espaço que o rodeia. Segundo Hall (apud, SOUSA E BRANDÃO 2008, p. 03) na pós-modernidade a construção do ser de um individuo é dinâmico e articulado, não existe “[...] a identidade, mas identidades”. Ou seja, para conhecer a identidade da mulher adolescente da periferia é preciso compreender as construções destas identidades distintamente e como elas se articulam.

Sendo assim, Sousa e Brandão falam que "O fato de ser adolescente e não ser ouvido (a) pelos adultos e pela sociedade é acrescentado ao fato de ser mulher e morar na periferia” (2008, p. 8). Desta maneira, são combinadas tanto a opressão de classe como a opressão de gênero. Neste contexto, ainda podemos acrescentar a desconfortável situação de o adolescente viver um estágio de descobrimento, da passagem da infância para a vida adulta, por mais que diversos autores sustentem que esta passagem é uma construção mais social do que simplesmente biológica.

\section{Gênero e Interculturalidade}

No decorrer da construção histórica e cultural, o gênero, conforme LOURO (1997), configura-se como constituinte da identidade dos sujeitos, ou seja, como processo de descoberta da identidade do ser humano onde comportamentos e aprendizagens se interligam nesse processo. Como a interculturalidade esta associada às relações de gênero? A história das mulheres está diretamente ligada ao surgimento do conceito de gênero, conceito este que possibilita problematizar as relações entre os sexos e firmando que tais relações não são naturais, mas construídas e remodeladas durante o processo histórico que é dinâmico. No decorrer desse processo esta envolvida toda uma cultura ligada a crenças, valores, preconceitos e costumes que envolvem as relações desiguais entre homens e mulheres. Nesta perspectiva as relações de gênero permitem que a interculturalidade tenha o reconhecimento dessas diferenças implicando dessa forma o respeito ao outro e à identidade cultural do seu semelhante.

Assim, o respeito pela cultura do Outro implica no reconhecimento de sua identidade cultural. Construindo dessa forma “[...] respeito pela linguagem, pela cor, o gênero, a classe, a orientação sexual, a capacidade intelectual”. (FREIRE, 2001, p.60) Para Freire, a interculturalidade esta ligada à aceitação e respeito pela cultura do outro. O importante é compreender a relação entre as culturas. No entanto é importante destacar que a cultura não é um todo uniforme muito menos homogêneo, a cultura constróise em estruturas sociais das quais fazem parte as relações de gênero.

A interculturalidade visa à mediação das diferenças culturais respeitando cada singularidade do ser humano que se constitui nas relações sociais de suas identidades. Martínez e Carreira (apud, SILVA 2003, p, 48) complementa que: "o termo intercultural possui um traço denotativo mais dinâmico que aponta para uma relação de interpenetração cultural, de ativa relação entre os membros de grupos humanos diferentes."

Por isso, ao relacionarmos interculturalidade e gênero observa-se que estes conceitos têm em comum o fato de rejeitarem lógicas de dominação ao se posicionarem de maneira semelhante em relação às dinâmicas de inclusão e exclusão social. Porém, também observamos que esses dois conceitos também têm especificidades diferentes, onde a interculturalidade define-se pelo posicionamento das relações entre grupos culturais enquanto a perspectiva de gênero denuncia a discriminação e desigualdades existentes entre os sexos.

\section{Gênero e inclusão social}

Se por um lado as desigualdades são construídas através da exclusão no acesso aos meios de produção ou ainda através de um acesso construído de modo a colocar setores da sociedade em posições desprivilegiadas. Por outro lado, é possível observar a construção das desigualdades na própria construção do lugar do homem e da mulher na sociedade.

[...] a insatisfação, o mal-estar de todo o ser humano quando se encontra em situações nas quais não pode realizar aquilo que deseja e ambiciona para si próprio e para a sua família. Partindo deste ponto de vista, a exclusão teria uma certa carga subjetiva, apoiada em ações materiais. Será igualmente necessário recordar que, por vezes, a exclusão que segue determinadas modas, hábitos ou ideias dominantes, pode ser vivida de forma positiva por uma pessoa, um grupo, uma comunidade, reforçando assim a sua coesão interna. (ESTIVILL, 2003, p.13)

A exclusão social facilita com que indivíduos sejam manipulados e controlados com mais facilidade firmando cada vez mais as desigualdades e diferenças tanto objetivas como subjetivas no que concernem as relaçoes socais em nossa sociedade.

Sendo que, o termo gênero surge de uma construção social e busca compreender as relações entre homens e mulher e suas relações de poder. Tendo em visto isso, se faz necesario, dialogar tais relações com todos os setores que fazem parte da sociedade. Dialogar e compreender tal termo tanto em espaços formais ou não formais faz com que o outro compreenda melhor sua condição enquanto sujeito.

Mas o que inclusão social tem haver com gênero? Primeiro que ao abordarmos sobre gênero, também estamos falamos sobre seus limites e desafios. E um deles é que tal discussão ainda não é um fator importante ou interessante para nossa sociedade; espaços formais não conceituam este termo tampouco discute as relaçoes de gêneros; a falta de políticas 
públicas voltadas a igualdade de gênero, nos faz subentender que a sociedade não esta preparada para um processo de “igualdade”, porém dentro de nossas diferenças. Contudo, ao se propor políticas pública de gênero exige estabelecer o sentido das mudanças, se as pretendemos com um caráter emancipatório (Souza Santos, Boaventura,1996). Dessa forma, para que as desigualdades de gênero sejam combatidas no contexto do conjunto das desigualdades sociais, se faz necessário uma prática cidadania para que assim se possa realizar uma justiça de gênero, começando principalmente pelo o Estado já que cabe a ele redistribuir riqueza e poder, entre regiões, classes, raças, etnias, e entre mulheres e homens.

\section{Metodologia}

Adotamos a pesquisa qualitativa entendendo que esta permite uma maior aproximação e compreensão de nossa problemática. Desta forma, Arpine (2003, p. 83) vem afirmar que "entendida como processo dialético, a pesquisa qualitativa procura conhecer profundamente o fenômeno, marcar sua singularidade em cada discurso sem, contudo perder de vista sua generalidade, sua condição de produção e sua ideologia.” Haguette (1992) ressalta que os métodos qualitativos enfatizam as especificidades de um fenômeno em termos de suas origens e de sua razão. Desta forma, compreende-se que a ação humana, interação social, e as transformações ocorridas estão interligadas a partir da história do passado e do presente.

Nessa perspectiva a pesquisa qualitativa nos permite conhecer e compreender de modo geral, durante a realização da pesquisa algumas questões que são colocadas de forma bem imediata, enquanto outras vão aparecendo no decorrer do trabalho de campo. Além do trabalho suas etapas a pesquisa qualitativas nos possibilita reflexões em torno dos problemas enfrentados, erros cometidos, escolhas feitas, dificuldades e descobertas.

\section{Procedimentos metodológicos}

Iniciamos com um estudo de textos a partir de autores que definem o conceito e histórico sobre gênero, inclusão e interculturalidade. Sintetizamos as ideias e apresentamos slides para debate em grupo. Utilizamos a exibição de um curta-metragem chamado “Acorda Raimundo, acorda!” onde os problemas sociais que as mulheres enfrentam perante a sociedade são abordados usando recursos audiovisuais ao inverter os papéis estereotipados do homem e mulher. A partir disto, deu-se início a uma roda de conversa onde foram levantadas as questões e confrontadas com experiências e visões pessoais das adolescentes. Logo depois, foi aplicada uma oficina pedagógica com o propósito de compreender a visão das adolescentes em relação ao Ser Mulher, no passado e no presente, com objetivo de relacionar os conhecimentos da pedagogia com os direitos das mulheres. Foi utilizada também uma apresentação de revistas com imagens de mulheres no cotidiano para levar à reflexão do "modelo" de mulher de ontem e de hoje que buscam homogeneizar o comportamento feminino.

\section{Resultados e discussão}

O bairro Sumaré está localizado no município de Sobral-CE sua população gira em torno de 16.060 habitantes e a maior parte é composta por adolescentes conforme o senso de 2010. As adolescentes pesquisadas consideram o bairro muito violento e ressaltam que crianças, idosos e suas famílias são expostas á violências ao presenciarem disputas de territórios entre gangues e principalmente o tráfico de drogas. A maioria da população é negra e muitas das adolescentes sentem na pele o preconceito e o machismo dentro de seu próprio bairro.

Mantemos contato com as adolescentes tanto devido o fato de morarmos no mesmo espaço geográfico, mas também pela atuação como professora substituta na escola do bairro e por ter realizado com as adolescentes oficinas sobre questões de gênero e feminismo. Mas como trabalhar e relacionar a interculturalidade a um estudo de gênero? Como a educação intercultural contribui para formação e discussões dos temas abordados?

Por morarem em um bairro extremamente violento e machista nota-se que as adolescentes pesquisadas estão nesses dois processos de inclusão e ao mesmo tempo de exclusão social. Nesse processo cabe ressaltar que suas subjetividades esta em direção à autonomia de construção de sua própria identidade, pois “[...] a identidade sempre diz respeito a uma tentativa de definir quem somos com quem nos identificamos e de quem nos diferenciamos” (SPOSITO 2010, p.115).

Contudo pelo fato da mulher ainda ser vista e tratada como "inferior", as adolescentes pesquisadas relatam seu cotidiano juntamente com as discriminações enquanto sujeito mulher de bairro. As dificuldades sócio-econômicas e culturais implicam em sua exclusão social, pois logo são estigmatizadas no processo de estratificação de classes.

Mas o que nos chama atenção é o fato dessas adolescentes entre 15 e 18 anos de idade chegam a interromper seus estudos pelo fato de precisarem trabalhar e ajudar seus pais, assim como cuidar do lar e cuidar de seus irmãos. Por estarem expostas às violências do bairro as adolescentes destacam que estão sendo privadas de um lazer adequado assim como também são impedidas de circularem entre as vizinhanças devido as disputas territoriais entre gangues. Com a falta significante de lazer, esportes, saúde entre outros ocorrem na uma insatisfação pelo fato do bairro não oferecer condições favoráveis de bem estar para elas.

Em encontros realizados com as adolescentes observou-se que mesmo morando no mesmo bairro, a diversidade de saberes e cultura das adolescentes contribuem para uma socialização e compartilhamento de diferentes idéias e saberes que contribuem para construção de relações e vínculos entre as adolescentes. 
Pois, por morarem em bairros periféricos, as adolescentes logo são vistas como desprovidas de saber/conhecimentos irrelevantes e cujas culturas são consideradas "insignificantes". No entanto é nesta insignificância que existe uma reprodução de opressão e da dominação. Neste contexto, a escola deveria contribuir para ampliar, conceituar e interligar cada conhecimento e diferentes modo culturais que cada aluno traz consigo, sempre focando e respeitando as diferenças dos sujeitos envolvidos, pois cada um carrega consigo suas origens, hábitos e costumes.

$\mathrm{Na}$ medida em que as adolescentes pareciam supervalorizar o status da pesquisadora enquanto universitária e por acharem que nós poderíamos ter mais conhecimento do que as pesquisadas, a princípio as adolescentes ficaram com receio de participar e de falar do significado de ser mulher em seu bairro. No decorrer das oficinas e das rodas de conversas começamos e criar um espaço de compartilhamento de conhecimento saberes, até porque não existe conhecimento superior, mais sim saberes diferentes, porém só conseguimos essa aproximação ao discutir e apresentar situações de mulheres que vivem em situação de opressão, que são excluídas, que sofrem violências físicas, entre outros. Tais assuntos não é "coisa de outro mundo" para elas, pois ao perceberem as relações propostas e discutidas com sua realidade as mesmas relatam que em seu bairro também sofrem com expressões do machismo, inclusive dentro de suas próprias famílias, principalmente entre seus pais e irmãos e cabe a elas juntamente com as mães a tarefa doméstica e, caso contrário, são punidas pelos homensmachistas da família, com violências físicas e simbólicas.

Parece-nos que devido à construção feita na sociedade e na própria escola em sacralizar e montar um pedestal em prol do conhecimento da universidade as jovens não percebiam as importantes contribuições que suas vidas diárias tinham para o tema abordado. Durante o processo foi feito enorme esforço da pesquisadora para desconstruir tais idéias no intuito de conseguir que as adolescentes perdessem suas inibições diante de uma universitária e assim pudessem se expressar de forma mais segura e sincera. Nota-se que as adolescentes têm um sentimento de valorização quando abordagens como estas sobre gênero e feminismo são levadas até elas, principalmente quando demonstramos a elas que suas vidas, culturas e saberes que elas acham "irrelevante"estão interligados a todo um contexto sócio-histórico social e cultural.

Nesta perspectiva a abordagem deste assunto não foi à toa, pois falar sobre feminismo é abordar as desigualdades, injustiças, machismo, sexo, cultura, crenças, cultura familiar, cultura religiosa e igualdade de gênero, que de certa forma contribuem para que as jovens não naturalizem as opressões que sofrem no cotidiano. Levando em conta que as adolescentes estão no ensino médio e assuntos como estes são deixados de lado nas escolas é compreensível que elas desconheçam sobre o gênero.
Mesmo neste quadro sombrio, paradoxalmente, muitas delas, apesar de não conhecerem conceitualmente a dominação machista, são contra a submissão da mulher. Sobre isso, uma das adolescentes pesquisadas afirma: "Eu não sabia dessas lutas das mulheres, só via que tem muita desigualdade, né. A gente às vezes não pode fazer as mesmas coisas que os homens.” (Joana). Outra adolescente analisa: "Por mais que tenha sido necessário que as mulheres de antes fossem expostas como ridículas, as lutas delas não foram em vão. Se hoje nos achamos um pouco independentes, isso foi graças a elas” (Tati).

Embora a discriminação e o preconceito ainda estejam muito vivos no cotidiano das adolescentes pesquisadas, para muitas delas ser mulher significa aquela que "trabalha, estudar, ganhar seu próprio dinheiro e não depender do marido. É aquela que não se submete as opiniões apenas para agradar seu companheiro". Contudo a experiência de troca de conhecimento com as adolescentes nos propiciou uma maior compreensão de suas realidades, pois conseguimos penetrar em suas realidades através do diálogo.

\section{Considerações finais}

Apesar das adolescentes viverem em um bairro considerado violento e predominantemente machista, suas concepções demonstram que a luta por independência não é algo totalmente desconhecido e em vão. Nota-se que as adolescentes são privadas do acesso destes temas, pois as maiorias das adolescentes desconheciam os contextos históricos das lutas das mulheres. Dessa forma, o estudo de gênero com as adolescentes permitiu um processo de construção de identidade além de proporcioná-las um conhecimento e reconhecimento do ser mulher tanto na sociedade como também em seu bairro.

Um dos resultados alcançados reside no fato de termos conseguido desenvolver uma metodologia capaz de dialogar com o nível de consciência das pesquisadas. Foi importante a reação de uma das adolescentes que, após os estudos e as discussões, levou os conhecimentos para a sua mãe e esta refletiu sobre a sua condição de ser mulher na sociedade, especificamente em seu bairro e na relação com seu marido e decidindo inclusive se separar do mesmo devido aos constantes abusos sofridos. Concretamente, influenciamos o ser mulher da mãe de uma adolescente que participou do grupo. Isso nos fez pensar que as relações interculturais e a troca de saberes acadêmico e do senso-comum podem ser diretos e indiretos. O que há de comum entre nós que temos quase a mesma faixa etária são as vivências comuns nas relações de gênero, mas que, a vida acadêmica me proporciona a reflexão teórica e crítica para interagir com as adolescentes pesquisadas. 


\section{Referências}

ARPINI, Dorian Monica. (2003.) Violência e exclusão: adolescência em grupos populares. Bauru, EDUSC.

COLL, C.; PALACIOS, J.; MARCHESI, (1995) Desenvolvimento psicológico e educação: Psicologia Evolutiva. Porto Alegre: Artes Médicas.

DELGADO, Andréia (1998). Escola e construção de gênero. Cadernos de educação, São Paulo.

ESTIVILL, Jordi (2003). Panorama da luta contra a exclusão social: Conceitos e estratégias. Genebra.

FREIRE, Paulo. (1959) Educação e atualidade brasileira . 2. Ed. São Paulo: Cortez.

FREIRE, Paulo (2001) Pedagogia dos sonhos possíveis. São Paulo: UNESP.

HAGUETTE, Teresa Maria Frota (1992). Metodologias qualitativas na Sociologia. 3.Ed., Petrópolis: Vozes.

LOURO, Guacira Lopes (1997). Gênero e, sexualidade $e$ educação: uma perspectiva pós-estruturalista. Petrópolis-RJ: Vozes.

SCOTT, Joan (1990). Uma categoria útil de analise histórica. Educação e Realidade, Porto Alegre-RS, v. 15, n.2, p. 5-22, jul./ dez.
SANTOS, Boaventura de Sousa. (1996). Pela mão de Alice: o social e o político na pós-modernidade. 2. Ed., São Paulo: Cortez. SPOSITO, Marilia Pontes. Movimentos sociais, controvérsias conceituais e práticas educativas. In: BONFIM, M.C.A do.; MATOS, K.S.A.L de.; GOMES, A.B.S.; SANTOS, A.C.S.; (Orgs). Educação e Diversidade Cultural. Fortaleza, Editora UFC, 2010, .p.108-122. SILVA, Ferreira Gilberto da. Multiculturalismo e Educação intercultural: vertentes históricas e repercussões atuais na educação. In: FLEURI, Reinaldo Matias (Org.) Educação Intercultural mediações necessárias. 2003. Rio de Janeiro: Editora DP\&A

\section{Sites consultados}

SOUSA, Ada Cristina Guimarães de; BRANDÃO, Shyrlene Nunes. Como é ser adolescente do sexo feminino na periferia? Disponível em: http://www.scielo.br/pdf/pcp/v28n1/v28n1a07.pdf Acesso em 25 de março de 2015. 